\title{
The organic era
}

\author{
The organic photonics industry has come of age in the past few years. Nadya Anscombe speaks to Marc Baldo \\ from the Massachusetts Institute of Technology, USA, about the advances that have been made and the \\ challenges that remain.
}

\section{Huge progress has been made in the last ten years in organic light-emitting diode (OLED) technology. What do you think are the most significant breakthroughs?}

As a community, we have solved the internal efficiency problem using phosphorescent dyes and we are making progress with the stability issue. The stability and efficiency of blue OLEDs could still be improved, but for many applications the current performance is sufficient. Although great improvements have been made in the internal efficiency, there is still room for improvement in the external efficiency of OLED devices. Innovations in the optical design of OLEDs, such as texturing the transparent substrate, can decrease the amount of light that is trapped in waveguide and surface plasmon modes.

\section{What are the main challenges that} are still to be overcome in the OLED displays industry?

The biggest challenge faced by the OLED display industry is only indirectly related to OLED materials themselves. It is, surprisingly, the stability of the silicon backplane. If someone had told me back in 1997 — when I first became involved with this technology that the stability of the silicon would be the problem in the future, I'd have laughed. Unlike other display technologies, the emission from an OLED is proportional to the current injected, making them especially sensitive to degradation in the backplane transistors that switch them on and off. Consequently, active-matrix OLED displays need especially reliable and stable transistors to drive them. This has meant that display manufacturers have had to use polycrystalline silicon for backplanes instead of less expensive amorphous silicon. Research is going on to try and solve this problem and companies are trying to develop new materials or use annealing techniques, but the problem remains. Another challenge is patterning a display, or defining the pixels. Most of the industry currently uses shadow masks, which are fine for small displays but are difficult to scale up to larger displays. When they are large they flex and also generate dust. Both of these are manufacturing issues. Although material

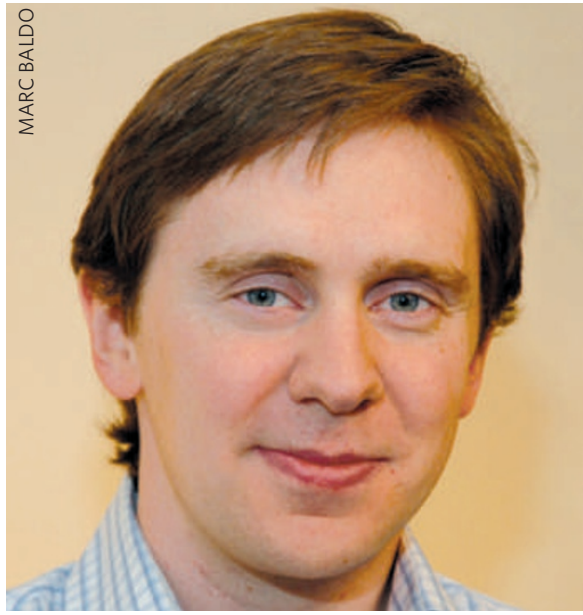

Baldo: "Achieving an electrically pumped organic laser is a daunting technical challenge."

development continues, most device issues have largely been solved - it is the manufacturing issues that now need attention.

\section{What trends are you seeing in emerging OLED products?}

There are already a lot of mobile phones using OLEDs, but for larger displays manufacturing problems are expensive to solve. This is why it is the big companies that are coming out with products first. For example, Sony has launched an OLED TV and it really does look beautiful. However, with a price tag of a few thousand dollars, these are more of a statement of technical and financial resources than a mass-market product at the moment. When OLED displays were first launched, one of the unique selling points was the possibility of flexible displays. Again, however, the problem is in the backplane, and to a lesser extent, the packaging. The display industry will probably not pursue flexible devices commercially until an economical solution is found for the backplane in conventional displays. With all the manufacturing issues that OLED displays are facing, many companies have instead turned their attention back to the idea of lighting applications particularly white light. OLEDs are ideal for large-area lighting applications and the big attraction of these applications is that they do not need patterning or an active matrix backplane - the two major issues in OLED display manufacture. So we are seeing major activities in OLED lighting, with some interesting products coming to market.

\section{What is happening in the organic} photovoltaics industry? Is it as mature and close-to-market as the OLED industry? The organic photovoltaics (PV) industry has also made huge advances over the last ten years, but it is behind the OLED industry in maturity. Although it does not suffer from the same manufacturing issues as the OLED industry, stability of the organic compounds is potentially a bigger issue because of the exposure to solar radiation. The industry also cannot compete with conventional technology on material costs alone. It is not enough to say that organic cells are cheaper to manufacture; even if a cell is cheap, if it is not efficient, this will be offset by installation costs and the customer will not make any savings. Competing technologies such as cadmium telluride (CdTe) are now achieving costs of $\$ 1$ per watt and their materials costs are estimated to be less than $\$ 0.05$ per watt, which doesn't leave much room for organics. Efficiency is of utmost importance and there has been good progress made in this area, particularly with polymer blends. By incorporating fullerenes into organic photovoltaic cells, efficiencies of over $6 \%$ have been achieved. This is a dramatic improvement and very exciting.

\section{What about other organic photonics} applications, such as the organic laser? Achieving an electrically pumped organic laser is a daunting technical challenge, but it isn't clear that it would solve any important commercial problems. Perhaps in the area of integrated photonics or green lasers, which are difficult to achieve using conventional materials, there may be scope for an organic laser. Of course, research into organic lasers may help to solve many issues that plague the OLEDs and PV industries, so research such as this is important.

\section{INTERVIEW BY NADYA ANSCOMBE}

Nadya Anscombe is a freelance science and technology journalist based in the United Kingdom. 